\title{
PHOTO-INTERPRETATION, DIGITAL MAPPING, AND THE EVOLUTION OF GLACIERS IN GLACIER NATIONAL PARK, B.C.
}

\author{
by
}

\author{
André Champoux and C.S.L. Ommanney
}

(National Hydrology Research Institute, Environment Canada, Ottawa, Ontario K1A OE7, Canada)

\section{ABSTRACT}

The inventory of Glacier National Park, B.C., has provided an opportunity to test a number of new procedures which might be applied to future Canadian glacier inventories. The objectives of this particular study were to complete a tripartite inventory based on available map and photo sources and develop an automated system of data acquisition and processing. The conjunction of the two has permitted an analysis of the evolution of the glaciers in this area during the last 100 years. The techniques used and a summary of the results are reported.

\section{INTRODUCTION}

Glacier National Park is located in the Columbia Mountains of south-eastern British Columbia. Its area of $1334 \mathrm{~km}^{2}$ contains 422 glaciers and some 15 hydrological basins (Figure 1). In 1977, at the invitation of the Warden Service of Parks Canada, the Glaciology Division of Environment Canada agreed to prepare an inventory of the glaciers as part of Parks Canada's resource inventory

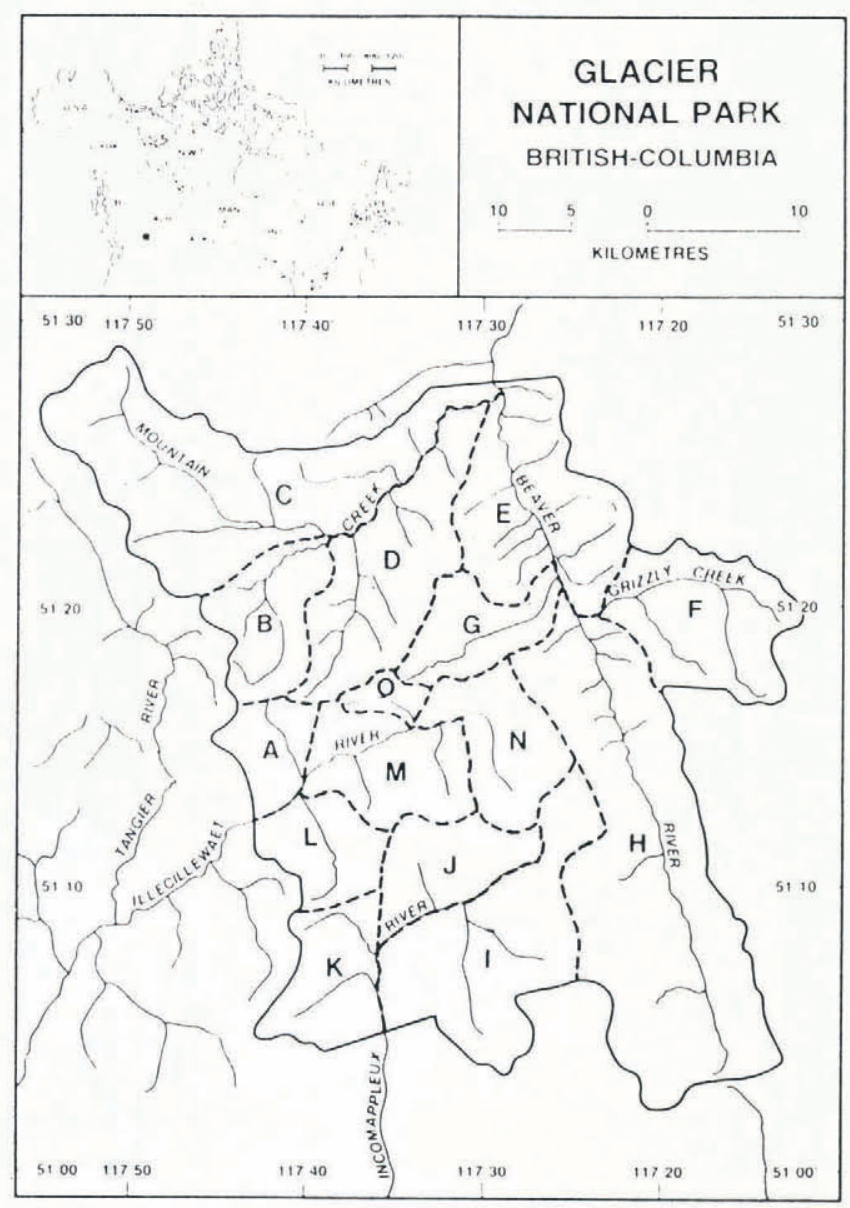

Fig.1. Location map. program. The standard photo base used for glacier inventories in British Columbia at that time was the provincial coverage from the early 1950 s, with a nominal photo scale of about 1:45000. Parks Canada funded a new air photo mission in 1978 which provided complete coverage of Glacier National Park at a scale of about 1:40 000. Using the above photography, the ice limits for the end of the Little Ice Age (approximately 1850) were reconstructed from moraine and vegetation indicators. Furthermore, to relate this inventory data to that from the rest of the province, it was necessary to determine the differences between 1951-52 and 1978. Thus, the scene was set for the tripartite inventory, reported here. It provided opportunities not only for assessing recent changes in the glacierized area, but also for developing and testing new techniques and procedures.

\section{PHOTO-INTERPRETATION}

Glaciers and related features were interpreted from the two sets of aerial photographs (1951-52 and 1978). Significant problems were created by the high relief and low flying height, which distorted the glaciers and mountain summits. The area of ice masses on steep slopes tends to be underestimated, due to their small spatial extent on the image. Fortunately, the seriousness of this problem is minimized by two factors. First, the change in angle from one image to the next alters the distortion and permits some compensation. Secondly, ice masses on steep slopes are relatively thin and unimportant in terms of the total ice volume.

The necessity of mapping each glacier three times, although tedious, highlighted differences between the images (e.g. shadows and clouds, etc.) and permitted immediate correction of errors in interpretation.

Photo-interpretation essentially followed the criteria discussed by Benoit and others (1985) and similar problems were encountered with the interpretation of debris-covered ice; these were partially rectified by field investigation. Special attention was paid to the interpretation of the limit of maximum recent glacier extent, deemed to correspond to the end of the Little Ice Age. This limit is usually quite obvious, since it is frequently surrounded by lateral and frontal moraines, is marked by a paucity of vegetation in comparison with the neighbouring unglacierized areas, and has a largely moraine-free zone between it and the snout of the present glacier. The frontal moraine is often cut by streams associated with melt water from the last century of retreat.

Differences between the 1951-52 and the 1978 photographs were observed to be largely related to changing appearance, rather than area of ice. In the latter years, the glaciers were more crevassed, had a steeper longitudinal profile - particularly at the snout - and a larger accumulation area, as is shown in the example from the Grand Glacier (Figures 2a, 2b).

\section{CARTOGRAPHY}

The information obtained from the aerial photographs was transferred to 1:50000 scale topographic maps, using a Zoom Transferscope when possible. This task was difficult when there were large slope and altitude differences. Height 

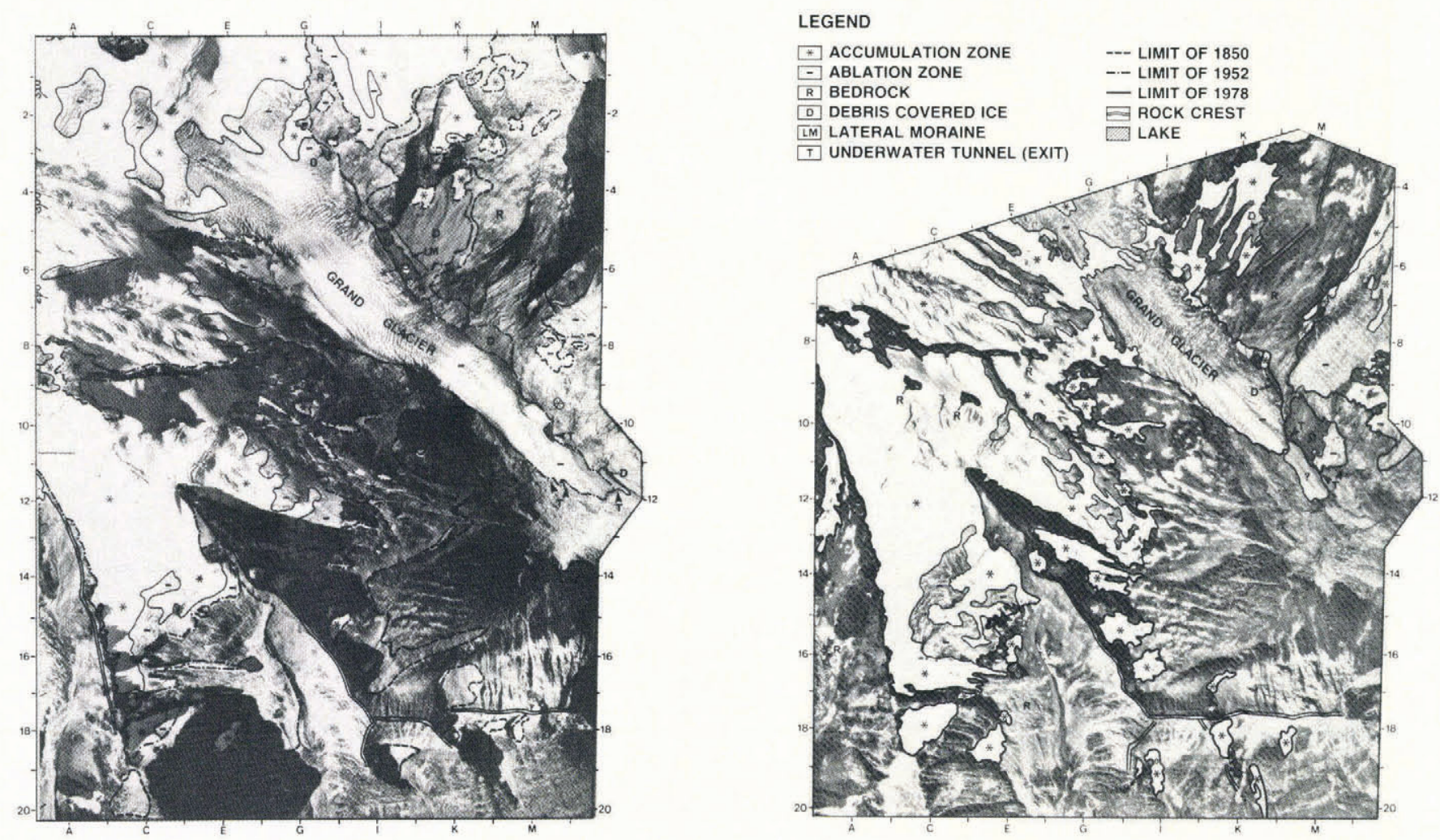

Fig.2. Photo-interpretation of Grand Glacier and vicinity.

(a). 1951 and 1850 limits. (b). 1978.

differences between valley bottoms and mountain peaks of ten exceeded $1000 \mathrm{~m}$. Frequent adjustments had to be made to the scale matching range and the distortion corrected by stretching the image. Occasionally the required corrections were too extreme to be accommodated so the operator, using identifiable features on the map and photograph, would sketch in the interpreted limits. The final adjustment was the interpolation of $100 \mathrm{~m}$ contours, as all the maps used are in English units.

\section{DIGITAL MAPPING}

To derive maximum benefit from the tripartite inventory, it was decided to expand the standard glacier inventory data sheet normally used for the Canadian Inventory (Ommanney and others 1973) to include data for the three periods together and supplement it with the area of ice within $100 \mathrm{~m}$ elevation bands. The depth estimates were determined according to the table used by Stanley (1970) for the Rockies. To improve the speed and quality of the measurements and analysis of data, digitizer and computer programs were developed. This work was carried out in three phases:

1. Digitizing of the various glacier boundaries and contour lines and storing the data on magnetic tape;

2. Transformation of the digitized data from binary into ASCII format and storage of the data; and

3. Calculation of the various data elements required for the inventory.

The first stage, digitizing each glacier, was accomplished using a Gradicon digitizer manufactured by Instronics Limited, an alphanumeric CRT terminal and Tektronics 4014-1 graphic terminal - all interfaced with a Hewlett-Packard (HP) 1000 mini-computer (Figure 3). The system supports a software package called AUTOMAP, written in PL-1. AUTOMAP was developed initially for the Canada Land Systems Division of the Lands Directorate, Environment Canada, to aid in the Canada Land Inventory. The software was modified to deal with the Canadian glacier inventory data (Whiffen unpublished report).

Digitizing takes place in an interactive mode, as follows: a) By identification of the outer limits of the hydrological basin to be measured. Four Universal Transverse Mercator (UTM) coordinate points are registered with a cursor to establish the relationship between the table coordinates and those of the 1:50000 scale work map. Using this information, all the appropriate scale conversions can be made. 
b) By continuous digitizing of each $100 \mathrm{~m}$ contour line; because the maps used are in English units, these had to be interpolated. Each line is assigned a separate code and displayed on the screen for checking and editing. Thus crossed contours and spiking can be eliminated immediately. Previously, insurmountable problems had been encountered in using a digitizer without any editing capability.

c) By digitizing the individual elements of the glacier, to each of which was assigned a special code. This was carried out three times, once for each of the time periods being recorded - Little Ice Age (mid 1800s), 1951 or 1952 (depending on the photographs available) and 1978.

The coordinates of the three maps were registered to the same UTM points so that the same contour line data could be used for both. No attempt was made to reconstruct the contour lines on the glaciers as they would have been during the Little Ice Age. Figure 4 illustrates a sample of the digitized data covering Grand Glacier as it

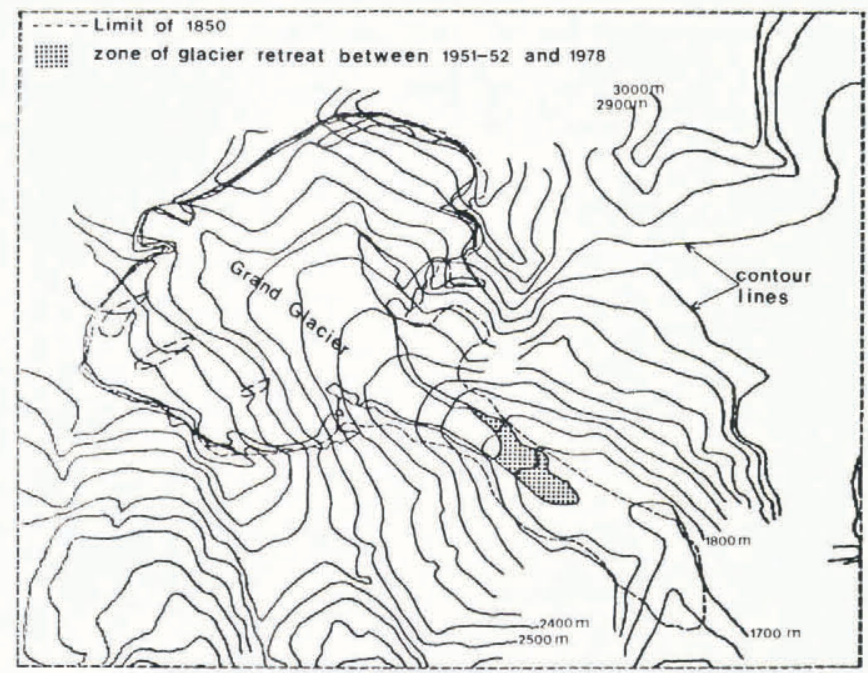

Fig.4. Tektronic screen output for Grand Glacier.

appeared on the Tektronic screen. Some numbers and letters have been added to the figure to make it more comprehensible. Thus one has some idea of the quantity of information stored, just for one glacier. Each line is represented by a whole series of individual coordinate points. Great care must be taken by the operator, particularly where the terrain is very steep, because $1 \mathrm{~mm}$ on the map can represent a displacement of $50 \mathrm{~m}$ or more in the limit of a glacier.

Once all the outlines have been verified, the data are stored on magnetic tape.

In the second stage, the binary data are transformed into ASCII using a short FORTRAN program with an HP-1000 mini-computer and written onto magnetic tape (C S Lam unpublished report).

The third, and final stage, involves the calculation of all the quantitative information required for the basic and supplementary glacier inventory data sets, using a CYBER 730 main frame computer. The product becomes part of the main inventory data base and is subject to various statistical analyses.

\section{DATA ANALYSIS AND RESULTS}

The statistical analysis of the Glacier National Park data required the development of a new program, different from that already in use, for the routine handling of Canadian inventory data. The range in types of data, both numeric and alphanumeric, as well as the large number of variables associated with any one glacier, necessitated several modifications to the statistical programs in use. The Statistical Package for the Social Sciences (SPSS) was chosen because of its versatility and ability to handle many calculations. It was available on the CYBER 730 and could be used in either batch or interactive mode.
Initially the data were grouped for analysis by individual hydrological basin. Later, all the data for the Park were read into a large matrix for complete analysis. Unique variable names are assigned to each numeric and alphanumeric field and an SPSS system file is defined. The program can then be used to retrieve the numerically coded variables. Many statistical procedures may be carried out on each of the glacier inventory parameters. Table I shows the mean values obtained for the most important inventory elements.

On average, the glaciers in the Park in 1978 lay between 2537 and $2167 \mathrm{~m}$ a.s.l. The change in elevation range can be seen in Table I. The data show that the glacier snouts rose an average of $131.2 \mathrm{~m}$ between 1850 and

\section{TABLE I}

\begin{tabular}{lrrr} 
Glacier Inventory Elements & 1850 & $1951-52$ & \multicolumn{1}{c}{1978} \\
\hline Mean Elevation (m) & 2282.2 & 2359.4 & 2341.6 \\
standard deviation & 222.5 & 213.2 & 220.1 \\
Highest Glacier Elevation (m) & 2541.0 & 2536.5 & 2537.3 \\
standard deviation & 271.8 & 288.9 & 265.0 \\
Minimum Glacier Elevation & & & \\
$\begin{array}{l}\text { (m) } \\
\text { standard deviation }\end{array}$ & 2057.0 & 2188.2 & 2167.0 \\
Total Glacier Area $\left(\mathrm{km}^{2}\right)$ & 320.0 & 224.5 & 213.0 \\
Total Ablation Area $\left(\mathrm{km}^{2}\right)$ & $?$ & 58.8 & 37.3 \\
Total Estimated Volume $\left(\mathrm{km}^{3}\right)$ & 18.2 & 10.4 & 11.1 \\
\hline
\end{tabular}

1951-52. Subsequently, a general re-advance took the lower limit of the glaciers to an elevation $21.2 \mathrm{~m}$ below that occupied at the latter date. The changes are mirrored in the values for the surface area. Between 1951-52 and 1978 there has been a general increase in surface area of $13.5 \%$. It is generally believed that it is the smaller features which are the most sensitive to changes in climate and this is borne out by the fact that these are the ones which have shown the greatest change. Stanley's table of depth estimates is not fine enough to draw any conclusions about recent changes in the volume of these small glaciers. Field observations in other glacierized areas have only been made on large glaciers, due to problems of resolution in the techniques used.

It is noticeable that the ablation area in 1951-52 was much greater than that in 1978. The lack of a common year for photography in the early 1950s might be seen as a problem; however, the differences in the height of the snowline in areas of overlap were small and the pictures were taken close to the end of the melt season. This was not the case in 1978, when some of the photographs were taken on July $24-25$ and the balance on August 3. Although the impact on the accumulation area ratio was high, all glaciers had exposed ice at their snouts, so the measured increase in glacierized area between the two dates is considered to be real.

\section{GLACIER TYPES}

Analysis of the inventory classification matrix reveals that, in this region of the Columbia Mountains, the ice masses are primarily mountain glaciers, split almost equally between niche and cirque glaciers with some ice aprons. The longitudinal profiles are usually regular. For the most part, the classifications have not changed over the three dates. However, several glacierets, mapped in 1978, did not exist in 1951-52. The increase in the number of these glacierets is largely responsible for the increase in the total number of glaciers in the Park - from 354 to $422-$ over this time period. 


\section{CONCLUSION}

As a result of this study, an operational procedure applicable to all aspects of the Canadian glacier inventory has been developed. The use of a chronological sequence of mapping-quality aerial photographs has permitted a detailed study of the evolution of a large group of glaciers lying within the Big Bend of the Columbia River. Power (1985) recently reported on the modelling of flows within the Columbia River basin and the importance of the glacier melt component. This study provides some information, albeit for a fairly small area, on the changes which have taken, and are taking, place and which should be considered in any modelling of sustained flow. The recording of changes in the smaller features, $<0.5 \mathrm{~km}^{2}$, could be particularly important as these tend to be overlooked in the map bases used. With over 100000 glaciers due to be inventoried in Canada, it will seldom be possible to provide the kind of spatial and temporal detail reported on here.

The use of the Lands Directorate digitizing system not only eliminated a great deal of the additional work occasioned by a tripartite inventory, but also established a commonality in the measurement system that further improved the accuracy. With colour-coded maps and procedures manuals, the measurements could be carried out by technicians thus freeing the glaciologists for the more critical interpretation phase.

Analysis of the data has shown that it is the smaller features, $<1 \mathrm{~km}^{2}$, which have reacted most quickly to the recent change in climate. Although the larger glaciers show evidence of thickening and re-advance, most have not yet re-occupied the positions they held in the early 1950s. One of the exceptions is the Illecillewaet Glacier which we have reported on elsewhere (Champoux and Ommanney 1986).

\section{ACKNOWLEDGEMENTS}

Thanks are extended to Parks Canada for initiating this study and providing some of the funding for it. We particularly appreciated the support of John Turnbull, Chief Park Warden, and his staff at Rogers Pass, and the interest and assistance of John Woods, Chief Park Naturalist.

\section{REFERENCES}

Benoit I, Champoux A, Ommanney C S L, Dubois J-M M In press Clef pour la photointerprétation des glaciers en milieu tempéré. Photointerprétation

Champoux A, Ommanney C S L 1986 Evolution of the Illecillewaet Glacier, Glacier National Park, B.C., using historical data, aerial photography and satellite image analysis. Annals of Glaciology 8: 31-33

Lam C S Unpublished Elevation bands, optimum elevations and mean elevation of a glacier. Ottawa, Environment Canada. Computing and Applied Statistics Directorate

Ommanney C S L, Clarkson J, Strome M M 1970 Information booklet for the inventory of Canadian glaciers. Ottawa, Department of Energy, Mines and Resources. Inland Waters Branch (Glacier Inventory Note 4)

Power J M 1985 Canada case study: water supply. International Association of Hydrological Sciences Publication 149 (Techniques for Prediction of Runoff from Glacierized Areas): 59-71

Stanley A D 1970 A pilot study for an inventory of the glaciers in the Rocky Mountains. Inventory of glaciers in the Waputik Mountains. In Perennial ice and snow masses; a guide for compilation and assemblage of data for $a$ world inventory. Paris, UNESCO/IASH, p. 36-46 (Technical Papers in Hydrology 1)

Whiffen S W Unpublished A procedure manual for digitizing the Glacier Inventory Project. Waterloo, Ontario, University of Waterloo. Department of Geography 